\title{
CFD modelling of the fast pyrolysis of biomass in fluidised bed reactors: Modelling the impact of biomass shrinkage
}

\author{
K. Papadikis ${ }^{\text {a }}$, S. Gu ${ }^{\text {b,* }}$, A.V. Bridgwater ${ }^{\mathrm{a}}$ \\ a School of Engineering and Applied Science, Aston University, Aston Triangle, Birmingham B4 7ET, United Kingdom \\ ${ }^{\mathrm{b}}$ School of Engineering Sciences, University of Southampton, Highfield, Southampton, SO17 1BJ, United Kingdom
}

\section{A R T I C L E I N F O}

\section{Article history:}

Received 31 October 2008

Received in revised form 22 January 2009

Accepted 22 January 2009

\section{Keywords:}

CFD

Fluidized bed

Fast pyroysis

Heat transfer

Biomass shrinkage

\begin{abstract}
A B S T R A C T
The fluid-particle interaction and the impact of shrinkage on pyrolysis of biomass inside a $150 \mathrm{~g} / \mathrm{h}$ fluidised bed reactor is modelled. Two $500 \mu \mathrm{m}$ in diameter biomass particles are injected into the fluidised bed with different shrinkage conditions. The two different conditions consist of (1) shrinkage equal to the volume left by the solid devolatilization, and (2) shrinkage parameters equal to approximately half of particle volume. The effect of shrinkage is analysed in terms of heat and momentum transfer as well as product yields, pyrolysis time and particle size considering spherical geometries. The Eulerian approach is used to model the bubbling behaviour of the sand, which is treated as a continuum. Heat transfer from the bubbling bed to the discrete biomass particle, as well as biomass reaction kinetics are modelled according to the literature. The particle motion inside the reactor is computed using drag laws, dependent on the local volume fraction of each phase. FLUENT 6.2 has been used as the modelling framework of the simulations with the whole pyrolysis model incorporated in the form of user defined function (UDF).
\end{abstract}

(c) 2009 Elsevier B.V. All rights reserved.

\section{Introduction}

Extensive research has been conducted recently in the renewable energy sources. The understanding of the major factors that affect biomass fast pyrolysis is of great importance. Shrinkage affects the mechanism of pyrolysis in various ways. Biomass properties (porosity, thermal conductivity, specific heat capacity, density, etc.) vary during the thermal degradation, resulting in different temperature gradient inside the particle, due to increase in density as the particle diameter decreases. As a consequence, the product yields are affected by the thinner and hotter char layer formed. In the present study, the shrinkage of biomass is modelled inside a $150 \mathrm{~g} / \mathrm{h}$ bubbling fluidised bed reactor, extending the already developed CFD model by the authors [1,2] for the simulation of biomass fast pyrolysis in fluidised beds. The kinetics mechanism used to model biomass pyrolysis is a two stage semi-global mechanism with kinetic constants by Chan et al. [3], Liden et al. [4] and Di Blasi [5].

\section{Background}

Fluidised beds are the most widely used type of reactor for fast pyrolysis, as they offer a number of advantages, such as high heat

\footnotetext{
* Corresponding author. Tel.: +44 238059 8520; fax: +44 2380593230 .

E-mail address: s.gu@soton.ac.uk(S.Gu).
}

transfer rates and good temperature control. The hydrodynamics of fluidised beds have been widely investigated, both experimentally and numerically, to allow validation of the model results. To date most of the computational research interest has been focused on the simulation of the fluidised bed hydrodynamics, using either the Eulerian (continuum) [6] or the Lagrangian (discrete element) model [7,8], and models like the one developed by Bokkers et al. [9] which is based on the modelling of the larger bubbles as discrete elements that are tracked individually during their rise through the emulsion phase, which is considered as a continuum. Due to the significant increase in computing power of recent years, these models have now made computational modelling of multiphase granular flows possible, though it is still very challenging, particularly so for industrial scale reactor units.

Compared to two-phase flows that have been extensively studied [10-13], the information for bubble three-phase flows is relatively limited $[13,14]$. The calculation of drag forces on particles that are part of a solid/liquid/gas mixture is a more complicated case and certain assumptions have to be made. Kolev [13] analyses the bubble three-phase flow by making the assumption that the solid particles are carried by the liquid or a gas/liquid mixture or the gas alone, depending on the local volume fraction of each one of the continuous phases. A detailed analysis of the momentum transport phenomena in fluidised bed reactors has been reported by the authors in [1].

The bed to surface heat transfer has been widely studied through the years for different cases, using different approaches $[15,16]$. 


\begin{tabular}{|ll}
\hline Nomenclature \\
$A_{i}$ & pre-exponential factor $(1 / \mathrm{s})$ \\
$B i$ & Biot number \\
$C_{D}$ & drag coefficient \\
$C_{p}$ & specific heat capacity $(\mathrm{J} / \mathrm{kg} \mathrm{K})$ \\
$d_{i}$ & diameter $(\mathrm{m})$ \\
$D$ & droplet diameter $(\mathrm{m})$ \\
$E$ & activation energy $(\mathrm{J} / \mathrm{mol})$ \\
$e_{S S}$ & restitution coefficient \\
$g$ & gravitational acceleration $\left(\mathrm{m} / \mathrm{s}^{2}\right)$ \\
$g_{0, s s}$ & radial distribution coefficient \\
$h$ & convective heat transfer coefficient $\left(\mathrm{W} / \mathrm{m}^{2} \mathrm{~K}\right)$ \\
$\bar{I}$ & stress tensor \\
$I_{2 D}$ & second invariant of the deviatoric stress tensor \\
$f$ & drag factor \\
$F_{i}$ & force $(\mathrm{N} / \mathrm{kg})$ \\
$k$ & thermal conductivity $(\mathrm{W} / \mathrm{mK})$ \\
$k_{\Theta s}$ & diffusion coefficient for granular energy $(\mathrm{kg} / \mathrm{sm})$ \\
$K_{g s}$ & gas/solid momentum exchange coefficient \\
$m$ & mass $(\mathrm{kg})$ \\
$N u$ & Nusselt number \\
$p$ & pressure $($ Pa) \\
$P r$ & Prandtl number \\
$r$ & radial coordinate $(\mathrm{m})$ \\
$R$ & universal gas constant $(\mathrm{J} / \mathrm{mol} \mathrm{K})$ \\
$R e$ & Reynolds number \\
$t$ & time $(\mathrm{s})$ \\
$T$ & temperature $(\mathrm{K})$ \\
$U_{0}$ & superficial gas velocity $(\mathrm{m} / \mathrm{s})$ \\
$u_{i}$ & velocity $(\mathrm{m} / \mathrm{s})$ \\
$V$ & volume $\left(\mathrm{kg} / \mathrm{m}^{3}\right)$ \\
$V_{g}$ & volume occupied by the pores $\left(\mathrm{kg} / \mathrm{m}^{3}\right)$ \\
$V_{S}$ & solid-phase volume $($ wood and char $), \mathrm{kg} / \mathrm{m}^{3}$ \\
$V_{S 0}$ & initial effective solid volume $\left(\mathrm{kg} / \mathrm{m}^{3}\right)$ \\
$w_{i}$ & free setting velocity $(\mathrm{m} / \mathrm{s})$ \\
&
\end{tabular}

\section{Greek letters}

$\alpha \quad$ shrinkage parameter

$\beta \quad$ shrinkage parameter

$\gamma \quad$ shrinkage parameter

$\gamma_{\Theta s} \quad$ collision dissipation of energy $\left(\mathrm{kg} / \mathrm{s}^{3} \mathrm{~m}\right)$

$\Delta H \quad$ heat of reaction $(\mathrm{J} / \mathrm{kg})$

$\varepsilon_{i} \quad$ volume fraction

$\Theta_{i} \quad$ granular temperature $\left(\mathrm{m}^{2} / \mathrm{s}^{2}\right)$

$\lambda_{i} \quad$ bulk viscosity $(\mathrm{kg} / \mathrm{sm})$

$\mu_{i} \quad$ shear viscosity $(\mathrm{kg} / \mathrm{sm})$

$\rho_{i} \quad$ density $\left(\mathrm{kg} / \mathrm{m}^{3}\right)$

$\tau_{v} \quad$ velocity response time (s)

$\overline{\bar{\tau}}_{i} \quad$ stresses tensor $(\mathrm{Pa})$

$\phi_{g s} \quad$ transfer rate of kinetic energy $\left(\mathrm{kg} / \mathrm{s}^{3} \mathrm{~m}\right)$

$\psi \quad$ mass fraction

\section{Subscripts}

av average

c char

con continuous phase

col collision

d droplet

D Drag

$\mathrm{dm} \quad$ disperse phase maximum packing

eff effective

fr frictional

g gas $g_{i} \quad$ initial gas and vapour phase (gas + tar)

$g_{f} \quad$ final gas and vapour phase (gas + tar)

$i \quad$ general index

$k \quad$ radial position

kin kinetic

$m \quad$ mixture

$\mathrm{mf} \quad$ minimum fluidisation

$p \quad$ particle

$s \quad$ solids

$T \quad$ stress tensor

$v \quad$ velocity

vm virtual mass

$w \quad$ wood

$0 \quad$ initial value

Boterill [17] and Yates [18] studied the heat transfer between a bubbling fluidised bed of smaller particles to a fixed cooling tube or a stationary wall. Agarwal [19] studied the heat transfer to a large freely moving particle in gas fluidized bed of smaller particles and Parmar and Hayhurst [20] tried to measure the heat transfer coefficient for freely moving phosphor bronze spheres (diam. 2-8 $\mathrm{mm}$ ) around a bed of hot sand fluidised by air. Also, studies on the influence of bed particle size to the heat transfer coefficient have been performed by Collier et al. [21] and a Nusselt number based on the thermal conductivity of the gas was derived for $\left(U \leq U_{m} f\right)$, while for $\left(U>U_{m} f\right)$ the Nusselt number appeared to have a constant value. Numerical investigations have also been performed using the Eulerian approach $[22,23]$ and the results showed a strong coupling between the local solid volume distribution and the heat transfer coefficients. They also showed a good agreement with the penetration theory [24] as well as the influence of the rising bubbles.

The shrinkage of biomass in pyrolysis has also been studied both experimentally $[25,26]$ and numerically [27-30]. The results have shown that both primary and secondary reaction paths are affected by the shrinkage of the char layer, and larger tar yields are predicted for shrinking particles. The progress of the pyrolysis reaction is controlled by the heat transfer rates inside the solid particle for small values of Biot number, while for large values, both the heat transfer and chemical reaction rate are important in determining the overall rate of reaction. Also, different shrinkage factors led to different model predictions as they were compared to experimental data. All of the models examined the impact of shrinkage on biomass pyrolysis and determined how the pyrolysis process can be affected.

Single particle models can provide a very good insight of how the progress of pyrolysis reaction is controlled and predict accurate product yields. However, they cannot define the effects that shrinkage would have on a biomass particle that is a part of a bubble three phase flow, regarding the momentum and heat transfer from a fluidised bed, as well as the efficient char and sand separation in the freeboard of the reactor. There is limited work on CFD simulation that combine fluidised bed hydrodynamics with simultaneous pyrolysis of discrete particles. To our knowledge the only work published on this aspect is the work done by the authors $[1,2,31]$. The scope of the current study is to further extend the model developed by $[1,2]$ and include the effect of shrinkage in the pyrolysing discrete biomass particles. The model can be a useful guide for reactor design since it takes into account the majority of the parameters that would affect the progress of pyrolysis, from the time that the particle will be injected into the fluidised bed, until it reaches the outlet of the reactor. 


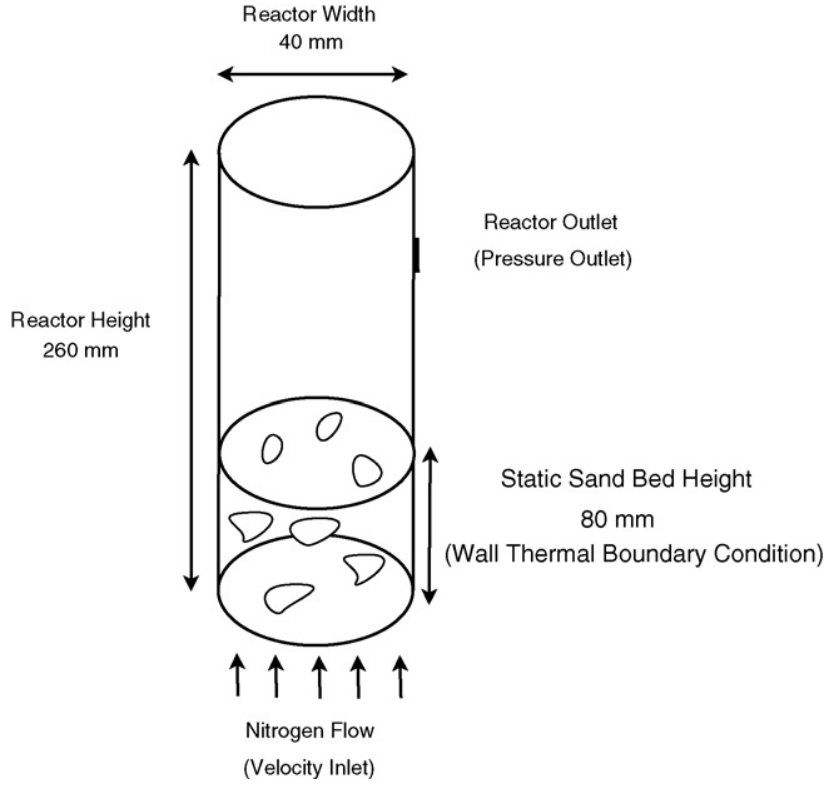

Fig. 1. Fluidised bed reactor geometry and boundary conditions.

\section{Model description}

The $150 \mathrm{~g} / \mathrm{h}$ fast pyrolysis lab scale reactor of Aston University is illustrated in Fig. 1. The shape of the reactor is circular with dimensions as shown in Fig. 1 and its walls are heated in the area where the sand bed stands. Nitrogen flows through a porous plate at the bottom of the reactor at a velocity of $U_{0}=0.3 \mathrm{~m} / \mathrm{s}$. The superficial velocity is approximately four times greater than the minimum fluidising velocity $U_{m f}$ of the reactor, which is typically around 0.08 $\mathrm{m} / \mathrm{s}$ using a sand bed with average particle diameter of $440 \mu \mathrm{m}$ Geldart B Group [32].

The two biomass particles are injected at the centre of the sand bed which has been previously fluidised for $0.5 \mathrm{~s}$. The particles are injected at the same time, one next to each other in order to achieve same initial conditions as much as possible. Momentum is transferred from the bubbling bed to the biomass particle as well as from the formed bubbles inside the bed. According to Bridgwater [33], the most appropriate biomass particles sizes for liquid fuel production lie in the range of $0.01-0.6 \times 10^{-2} \mathrm{~m}$ with temperature between 700 and $800 \mathrm{~K}$. The studied biomass particle is chosen to be $0.05 \times 10^{-2} \mathrm{~m}$ in diameter, which is more or less the size of the particles, due to feeding problems, for a small rig like the one studied in this paper. Bigger rigs and commercial plants use larger particles in the range of $2-5 \mathrm{~mm}$.

Depending on the regime of interest the heat transfer on the surface of the particles will be computed according to the literature. When the particle is carried only by the fluidising gas the wellknown Ranz-Marshall [34,35] correlation is used, while, when the particle is found inside the bubbling bed the heat transfer coefficient is calculated according to the findings of Kuipers et al. [24].

The reaction kinetics is based on a two-stage, semi-global mechanism, with kinetic constants suitable for wood pyrolysis according to Chan et al. [3] for the primary stage and Liden et al. [4] and Di Blasi[5] for the secondary reactions. This scheme has been chosen for this study because it can predict the correct behaviour of wood pyrolysis including the dependence of the product yields on temperature $[3,30,36]$.

The scope of the simulation is to determine the correct heat and momentum transport inside the reactor and inside the shrinking biomass particles. When the particles are injected inside the reactor, they can either be inside a bubble or inside the packed bed.
The code will be able to identify the regime of interest, depending on the local volume fraction of the two continuous phases, and calculate the correct drag, buoyancy and virtual mass forces according to the state, as well as the correct bed to surface heat transfer coefficient. The shrinkage of the particles will result in different particle volumes as well as different heat transfer conditions. It will be investigated whether shrikage of biomass will significantly affect the product yields as well as the momentum transport from the bubbling bed to the particles.

\section{Shrinkage parameters}

The mathematical model for heat, mass and momentum transport incorporated as a UDF in FLUENT and analytically described by the authors in $[1,2]$, is given in Appendix A. The current section introduces the shrinking parameters applied to the discrete particles.

The volume occupied by the solid structure of the particle is assumed to decrease linearly with the wood mass and to increase with the char mass, by a chosen shrinkage $\alpha$, as devolatilization takes place.

$\frac{V_{S}}{V_{w 0}}=\frac{m_{w}}{m_{w 0}}+\frac{\alpha m_{c}}{m_{w 0}}$

The volume occupied by the volatiles is made by to contributions. The first is due to the initial volume occupied by the volatiles $V_{g 0}$, and the second by the fraction $\beta$, of the volume left by the solid as consequence of devolatilization $\left(V_{w 0}-V_{S}\right)$

$V_{g}=V_{g 0}+\beta\left(V_{w 0}-V_{S}\right)$.

To account for structural changes during pyrolyis, $V_{g 0}$ also varies linearly with the composition of the degrading medium from an initial value $V_{g i}$ determined by the initial solid porosity to a final value taken as a fraction, $\gamma$ of the initial one $\left(V_{g f}=\gamma V_{g i}\right): V_{g 0}=$ $\eta V_{g i}+(1-\eta) V_{g f}$, where $\eta=m_{w} / m_{w 0}$. Thus, the total volume is expressed as

$V=V_{S}+V_{g}=\eta V_{g i}+(1-\eta) \gamma V_{g i}+\beta\left(V_{w 0}-V_{S}\right)+V_{S}$.

Table 1

Simulation parameters.

\begin{tabular}{lll}
\hline Property & Value & Comment \\
\hline Biomass density, $\rho_{w}$ & $700 \mathrm{~kg} / \mathrm{m}^{3}$ & Wood \\
Biomass particle diameter, $d_{p}$ & $0.05 \times 10^{-2} \mathrm{~m}$ & Fixed \\
Biomass specific heat capacity, $C_{p_{w}}$ & $1500 \mathrm{~J} / \mathrm{kg} \mathrm{K}$ & Wood \\
Char specific heat capacity, $C_{p_{c}}$ & $1100 \mathrm{~J} / \mathrm{kg} \mathrm{K}$ & Char \\
Biomass thermal conductivity, $k_{w}$ & $0.105 \mathrm{~W} / \mathrm{mK}$ & Wood \\
Char thermal conductivity, $k_{c}$ & $0.071 \mathrm{~W} / \mathrm{mK}$ & Char \\
Supericial velocity, $U_{0}$ & $0.3 \mathrm{~m} / \mathrm{s}$ & $\approx 4 U_{m f}$ \\
Gas density, $\rho_{g}$ & $0.456 \mathrm{~kg} / \mathrm{m}^{3}$ & Nitrogen $(773 \mathrm{~K})$ \\
Gas viscosity, $\mu_{g}$ & $3.44 \times 10^{-5} \mathrm{~kg} / \mathrm{ms}$ & Nitrogen $(773 \mathrm{~K})$ \\
Gas specific heat capacity, $C_{p, g}$ & $1091.6 \mathrm{~J} / \mathrm{kg} \mathrm{K}$ & Nitrogen $(773 \mathrm{~K})$ \\
Gas thermal conductivity, $k_{g}$ & $0.0563 \mathrm{~W} / \mathrm{mK}$ & Nitrogen $(773 \mathrm{~K})$ \\
Solids particle density, $\rho_{s}$ & $2500 \mathrm{~kg} / \mathrm{m}^{3}$ & Sand \\
Sand specific heat capacity, $C_{p, s}$ & $835 \mathrm{~J} / \mathrm{kg} \mathrm{K}$ & Fixed \\
Sand thermal conductivity, $k_{s}$ & $0.35 \mathrm{~W} / \mathrm{mK}$ & Fixed \\
Mean solids particle diameter, $d_{s}$ & $440 \mu \mathrm{m}$ & Uniform \\
& & distribution \\
Restitution coefficient, $e_{s s}$ & 0.9 & Value in literature \\
Initial solids packing, $\varepsilon_{s}$ & 0.63 & Fixed value \\
Static bed height & $0.08 \mathrm{~m}$ & Fixed value \\
Bed width & $0.04 \mathrm{~m}$ & Fixed value \\
Heat of reaction & $\Delta H=-255 \mathrm{~kJ} / \mathrm{kg}$ & [37] \\
Shrinkage parameters & $\alpha=1, \beta=0, \gamma=1$ & Values in literature \\
Reactor central axis, & $\alpha=0.5, \beta=0, \gamma=0.5$ & \\
$\alpha=0.5, \beta=0, \gamma=0.5 p a r t i c l e$, & $(-0.002,0.04,0.0)$ & Along the height of \\
$\alpha=1, \beta=0, \gamma=1$ particle & $(0.002,0.04,0.01)$ & Injection point \\
Injection point \\
\hline
\end{tabular}




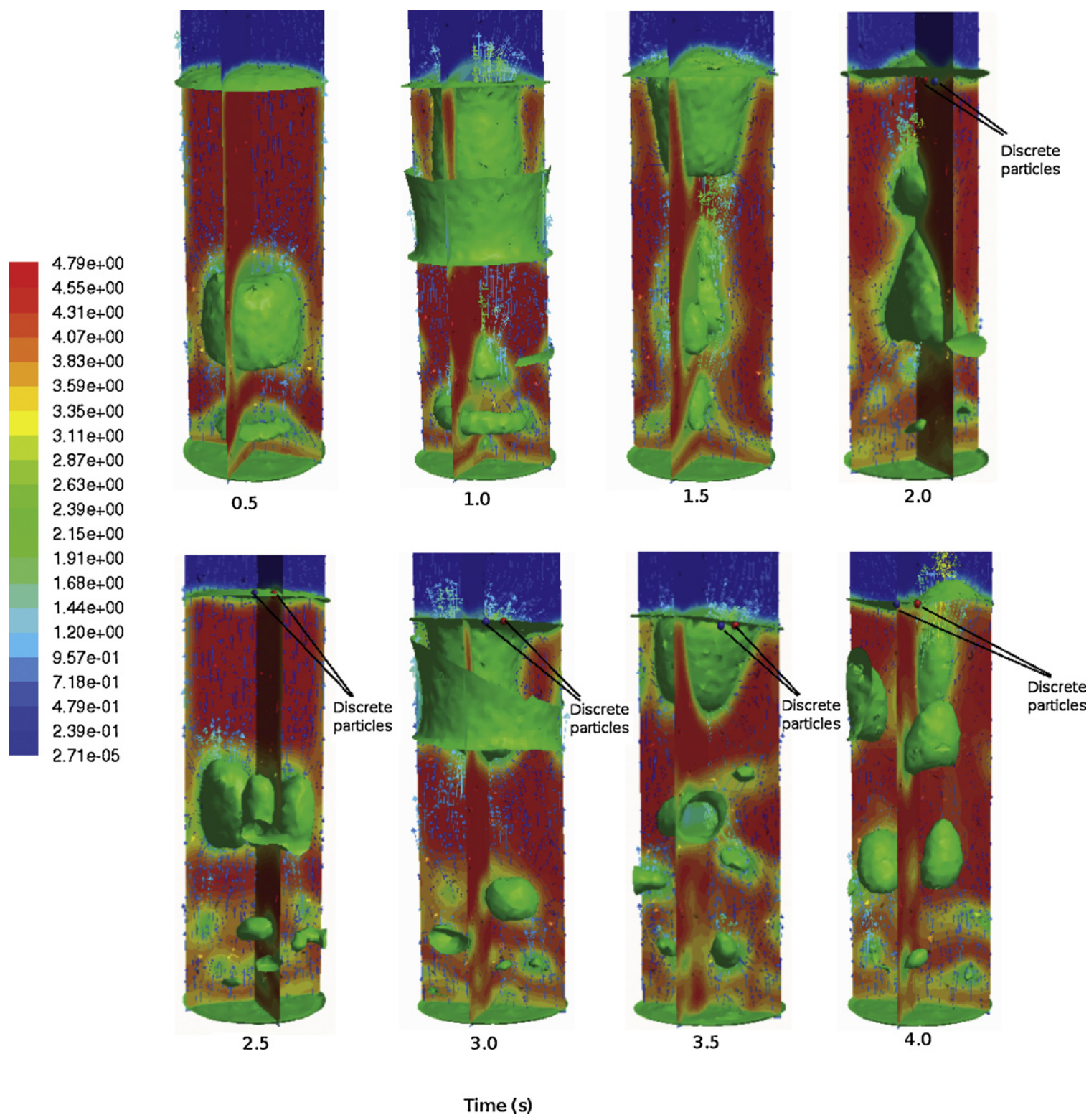

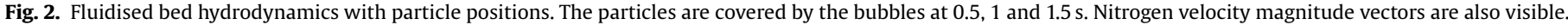

In this study, the initial effective solids volume $V_{w 0}$ is taken as half of the initial biomass concentration. The shrinkage parameters were chosen to be different for each one of the injected particles.

1. $\alpha=1, \beta=0, \gamma=1$ (shrinkage equal to the volume left by the solid devolatilization)

2. $\alpha=0.5, \beta=0, \gamma=0.5$.

The model will examine whether the differences in the shrinkage parameters will result in different particle behaviour inside the bed regarding heat and momentum transport from the fluidised bed, as well as product yields and residence times.

\section{Model parameters}

For the implementation of the model certain parameters have been quantified and assumptions made, in order to provide, as much as possible, an insight to the fast pyrolysis process in bubbling beds.
- The reactor uses $\approx 350 \mu \mathrm{m}$ in diameter particles as feed. The particles used in the model were chosen to be $500 \mu \mathrm{m}$ in diameter This was actually done to increase the Biot number as much as possible in order to get a relatively higher temperature gradient inside the particle.

- The particles used in the simulation were assumed to be totally spherical, whereas the particles used in experiments can be found on all sorts of shapes. The actual sphericity of the particles greatly differs from 1.

- The particles were injected very close to each other, to achieve similar heating and momentum transport conditions for both of them. In this way, the shrinkage effect can be quantified and compared.

- The model does not take into account the vapour evolution from the discrete phase, as this would slow down the simulation significantly. The mass sources though are calculated by the code, however they are not loaded in the simulation and not released in the computational domain. The inclusion of the tiny amount of mass source of vapours that are produced in each time-step has a major impact in the computational time of a 3D simulation 

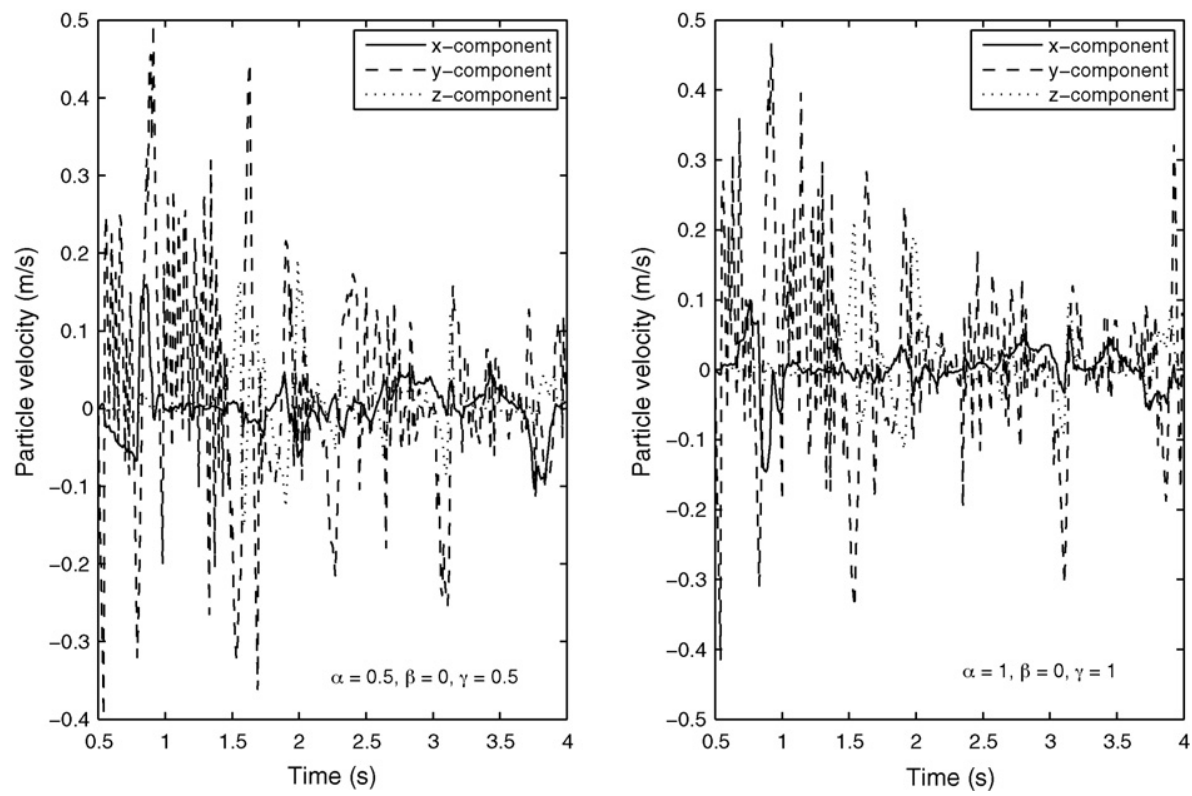

Fig. 3. Velocity components of particles with different shrinkage conditions.

like the one performed in this study. For a complete analysis of the vapour evolution the reader is referred to the study of the authors in this aspect [2].

The simulation parameters are shown in Table 1.

\section{Results and discussions}

\subsection{Bed hydrodynamics and particle positions}

Fig. 2 illustrates the hydrodynamics of the fluidised bed at different simulation times together with the positions of the particles. The particles cannot be noticed at the first two snapshots (0.5-1.5 s contours), due to the formation and evolution of a large bubble close to the injection point. Also, the velocity magnitude vectors of nitrogen are plotted to illustrate the motion and velocity of nitrogen inside the bed, since it plays a significant role in the heat and momentum transport to the biomass particles. For the first $0.5 \mathrm{~s}$ of the simulation the bed is fluidised without the biomass particles injected in it. Since the sand has gained some velocity, the

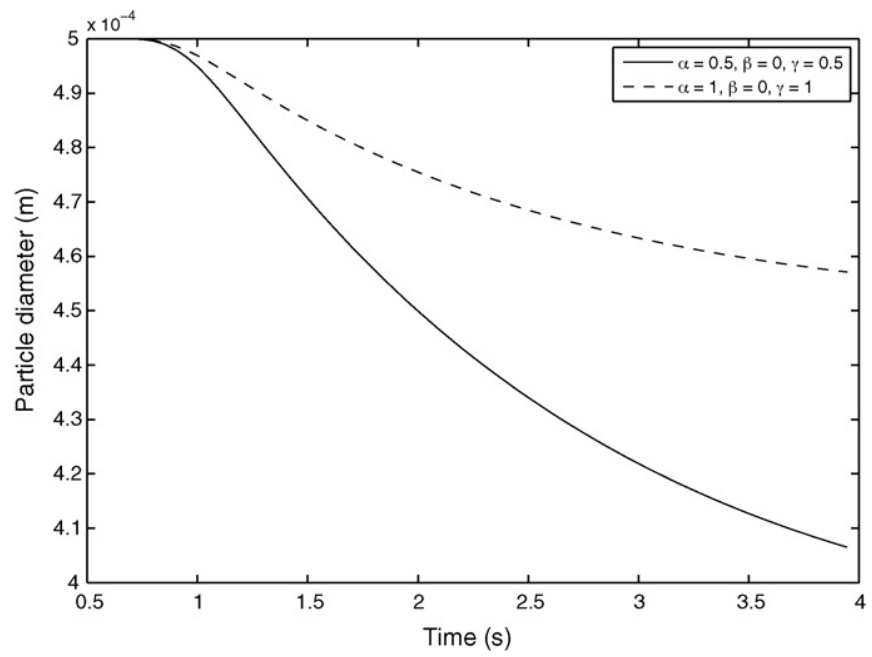

Fig. 4. Reduction in particle diameters during pyrolysis due to shrinkage. biomass particle are injected and momentum is transferred from the fluidised sand to the particles.

As we can see, a big bubble has been formed surrounding the injection point at $0.5 \mathrm{~s}$ and the two particles are immersed into the bubble. Thus, at the early stages of the simulation the momentum and heat is mainly transferred from nitrogen and not the sand. As the simulation progresses, the bubbles decrease in size and the biomass particles have moved on to the surface of the bed and close to the front wall and stayed there for the rest of the $2 \mathrm{~s}$ of the simulation.

From the simulation point of view, the injection of the particles at $0.5 \mathrm{~s}$ of fluidisation is a good choise since the sand and nitrogen have gained some velocity in all directions and the interactions between the bubbling bed and the discrete particles can be quantified. It also reduces the computational time significantly. However, from the process optimisation point of view, the injection of the particles should wait for some seconds until the bed has reached a more stable fluidised state and the solids distribution is more homogeneous. As we can see the diameter of the bubbles formed at the initiation of the fluidisation greatly exceeds the ones that

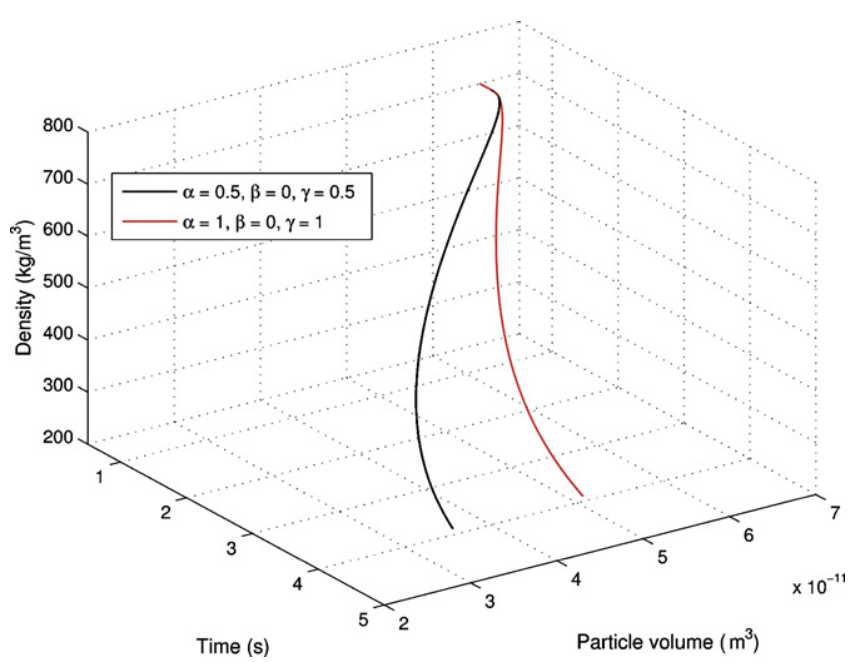

Fig. 5. Reduction in particle volume and density during pyrolysis due to shrinkage. 

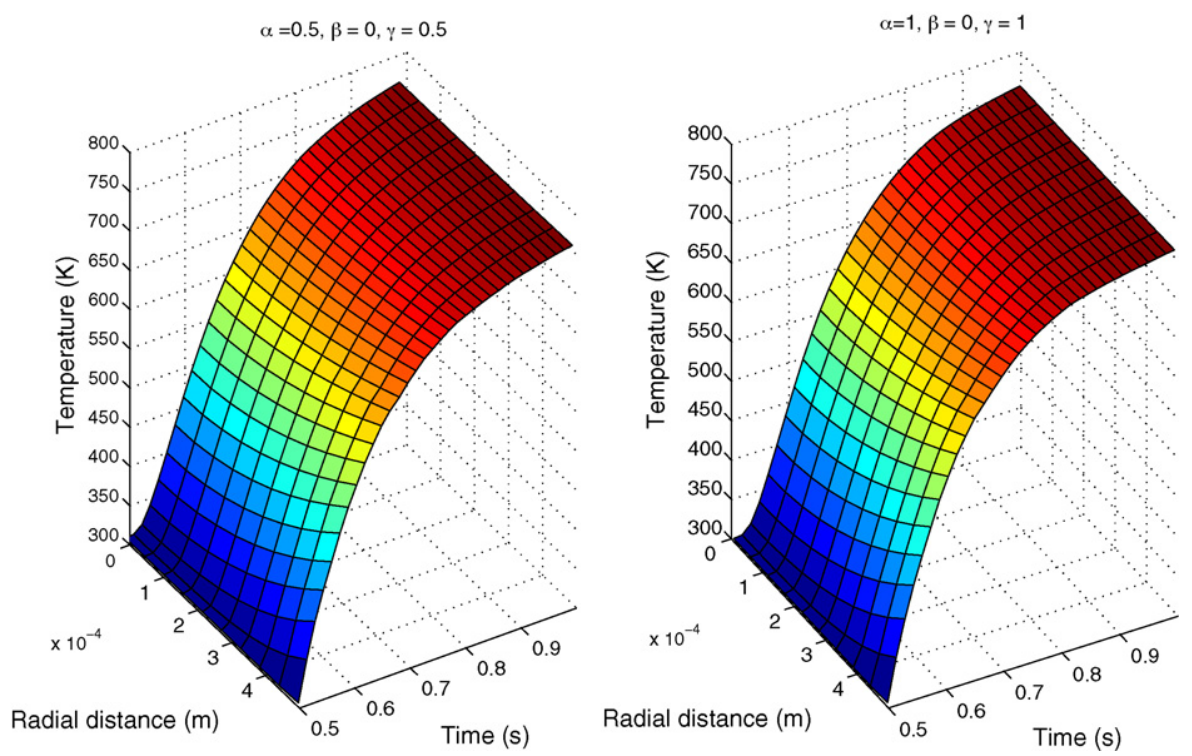

Fig. 6. Temperature distribution for particles with different shrinkage conditions.

follow in the next seconds. This is the main reason that the particles have been pushed close to the wall of the reactor, something that makes difficult their entrainment from the reactor after thay have been pyrolysed.

\subsection{Particle dynamics}

The velocity of the particle is calculated by integrating in time the equation of motion for discrete particles (Eq. (24)), and their new position is illustrated by the red and blue spheres inside the reactor (Fig. 2). The particle's position in the reactor is a result of the heat transfer and phase change due to reaction effects. Different heat transfer rates will result in different biomass degradation rates and consequently different particle properties in time. The density drop of the particle will differ and the drag and virtual mass forces exerted on the particle will significantly change. The model can predict the particle position inside the reactor, as it is subjected to pyrolysis, taking all of these effects into account.

Fig. 3 illustrates the velocity components of the particles as they move inside the reactor. In Section A.2, the various parame-

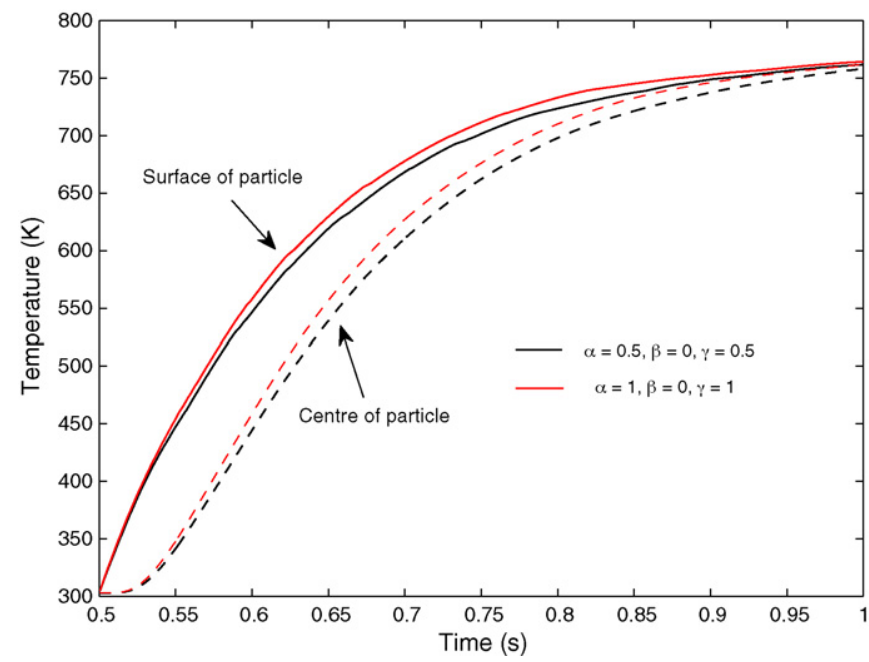

Fig. 7. Surface and centre temperatures for particles with different shrinkage conditions. ters that affect the motion of the discrete particles were discussed and it is really obvious that the most important physical ones are the diameter of the particles and their density, since they highly define the drag, virtual mass, gravitational and buoyant forces. In Fig. 3 we cannot easily distinguish if the shrinkage of the particles plays an important role in the development of their motion. However it can be claimed that the particle with the higher shrinkage conditions ( $\alpha=0.5, \beta=0, \gamma=0.5$ ) appears to have higher velocities especially in the $y-z$ direction than the less shrinking one ( $\alpha=1, \beta=0, \gamma=1$ ). At some points the velocity difference of the particles can exceed $0.1 \mathrm{~m} / \mathrm{s}$ as in the situation of the $1.7 \mathrm{~s}$ of simulation.

The reason for this, since almost identical momentum is tranferred to both particles, is the different reduction in diameter and density of the two particles due to shrinkage. Fig. 4 shows the reduction in the diameter of the particles because of the different shrinkage conditions and we can see that the final difference is close to $50 \mu \mathrm{m}$. The decrease in the diameter of the particle affects the velocity response time (Eq. (25)) and makes the particle more vulnerable to fluid velocity fluctuations. Also, Fig. 5 shows the change

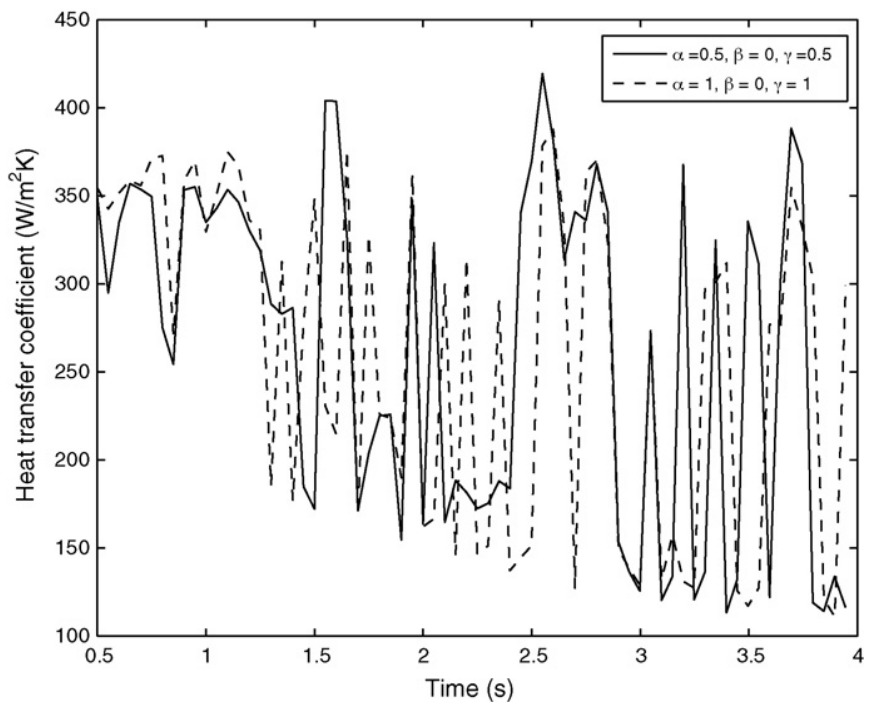

Fig. 8. Heat transfer coefficient for particles with different shrinkage conditions. 

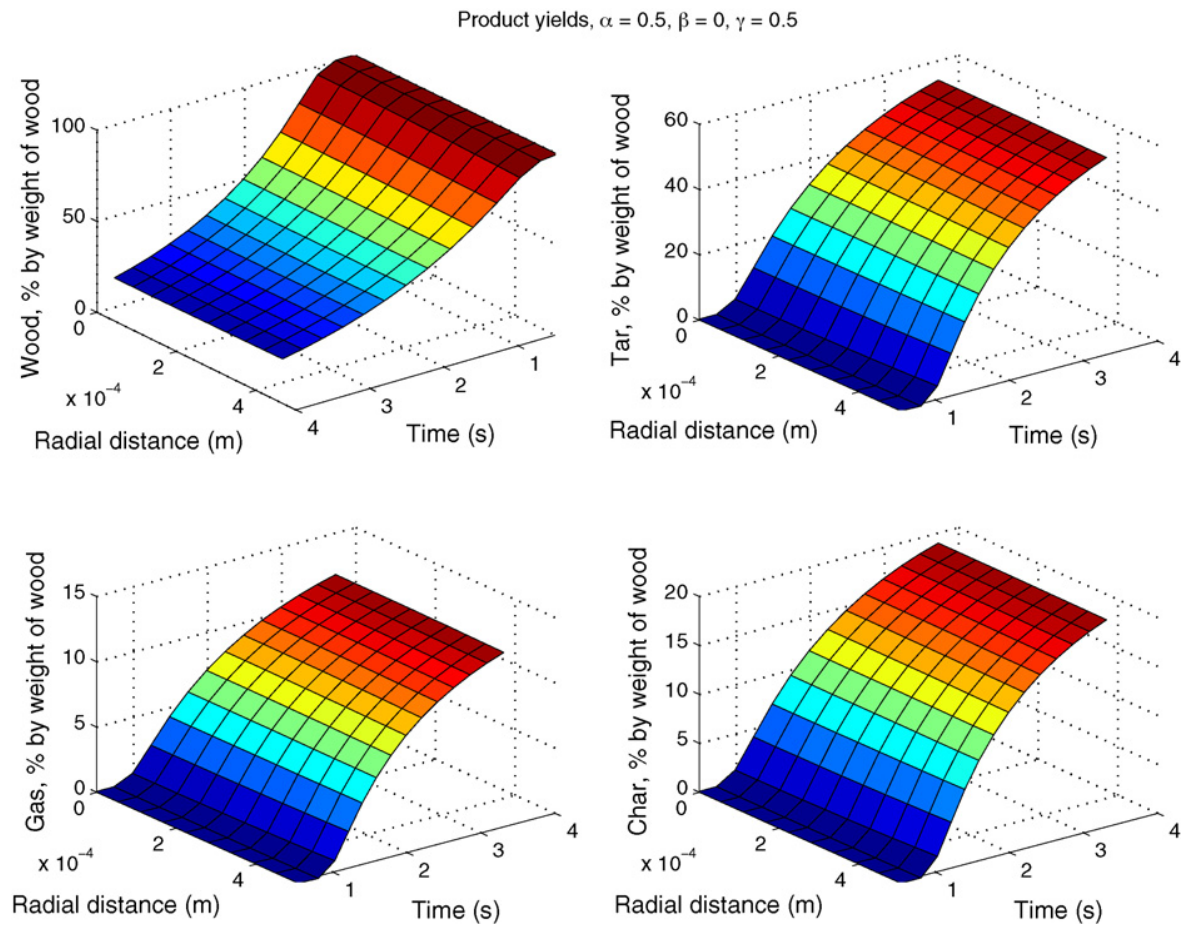

Fig. 9. Product yields for shrinking conditions $(\alpha=0.5, \beta=0, \gamma=0.5)$.

of particle volumes and densities with time. We can see that the particles result in almost identical densities at the end of the simulation with different volumes. This means that the mass of the products produced during pyrolysis was proportional to the volume occupied by the particles. However, the small size of the particles does not allow us to to easily estimate the effect of shrinkage on the dynamics of the particles, since the dimensional differences are in the order of microns. As a general conclusion someone could argue that shrinkage has a negligible effect on particle dynamics in the sub-millimeter scale. For a complete analysis and discussion of all
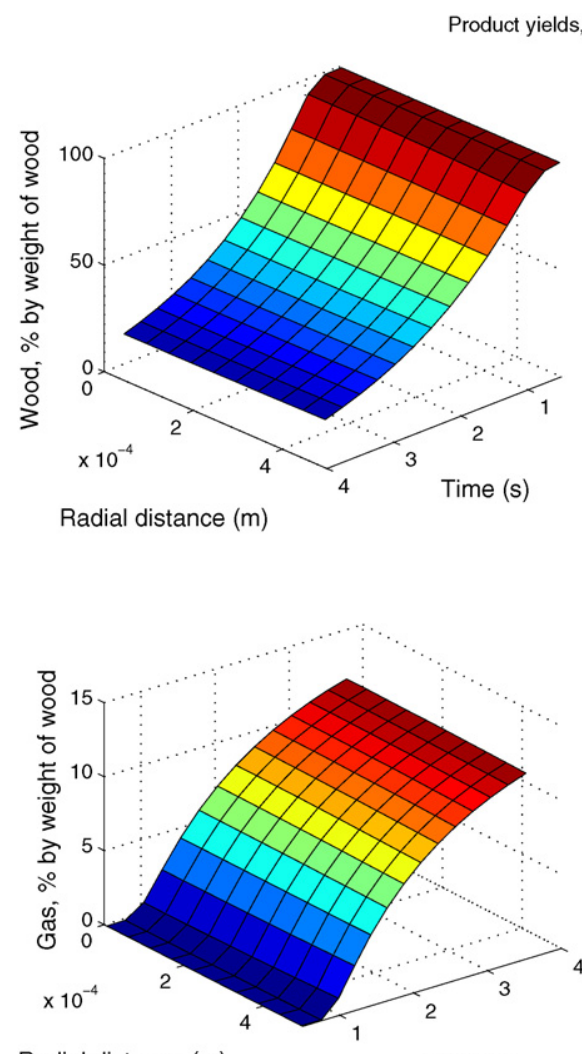

Radial distance (m)

Time (s)

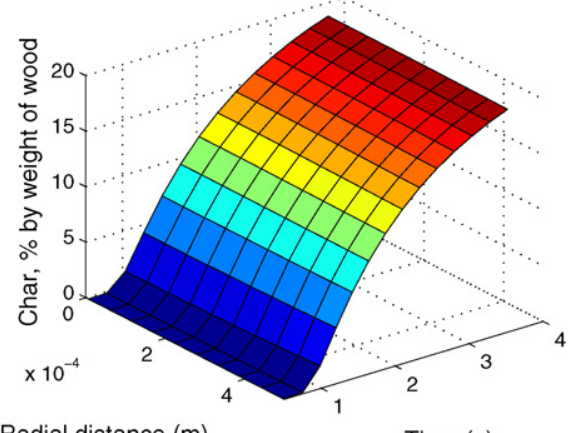

Fig. 10. Product yields for shrinking conditions $(\alpha=1, \beta=0, \gamma=1)$. 
the forces that act on the particle the reader is referred to the study of the authors in this aspect [1].

\subsection{Heat transfer and product yields}

Fig. 6 shows the temperature distrbution inside the two pyrolysing biomass particles. We can see that the particles have reached the reactor temperature in almost $0.5 \mathrm{~s}$, something which is typical for the heat transfer rates that the fluidised beds provide. The temperature gradients inside the two particles are almost identical, since the particles will start degrading after their temperature has reached $\approx 400^{\circ} \mathrm{C}$. The temperature at the surfaces and centres of the two particles can be seen in Fig. 7 and notice that minor differences occur in the heating rates of the two particles.

The heat transfer coefficient for both particles at different times is shown in Fig. 8. The points that the heat coefficient is reduced is when the particle finds itself in a low velocity but high concentration of nitrogen and convection is the dominant heat transfer mechanism. When the heat coefficient is high, conduction is dominant and the particles are located inside a high concentration of sand. The heat transfer coefficient is more or less the same for both particles, however as we are getting to the half and towards the end of the simulation the heat transfer coefficient for the highly shrinking particle seems to be slightly higher than the less shrinking one. This obviously occurs because the heat transfer coefficient depends on the physical parameters of the particle such as density and consequently mass and surface area. These differences can be up to $\approx 40 \mathrm{~W} / \mathrm{m}^{2} \mathrm{~K}$ towards the end of the simulation. This effect though plays a negligible role in the degradation of the particle because at the time that it happens, the particles have already reached the temperature of the reactor and the surface heat transfer coefficient cannot control their rate of degradation. The rapid heating that usually occurs in fluidised beds and the small size of the particles that result in a very small Biot number (in this case for an average heat transfer coefficient of $250-300 \mathrm{~W} / \mathrm{m}^{2} \mathrm{~K}$, $B i \approx 0.174$ ), causes the particles to be rapidly heated with negligible heat transfer resistance. The fact that the particle will start to react at $\approx 400^{\circ} \mathrm{C}$ makes the effect of the heat transfer coefficient and shrinkage even less intense. As it is shown in Figs. 6 and 7 the particles have reached a uniform temperature distribution along their radius due to their small size, when the surface temperature has reached $\approx 673 \mathrm{~K}$.

Figs. 9 and 10 show the radial distribution of the products. We can see that the different shrinkage conditions do not have a significant impact on the product yields and pyrolysis time of the particles. The differences on the product yields cannot exceed $1 \%$ in any case. Thus, the pyrolysis of thermally thin particles where the resistance to the internal heat transfer is very small compared to the external one, results to small residence times of volatiles inside the particle and secondary reactions have minor impact to product yields. The flat profile of the radial product distribution is due to the small Biot number of the particles, which resulted in a relatively uniform temperature distribution. In both cases the wood concentration was decreased to $\approx 19 \%$ by its initial weight. Tar yields were as high as $\approx 51 \%$, while gas and char yields $\approx 11 \%$ and $\approx 19 \%$ by weight of wood, respectively. According to [36] the same reaction kinetics scheme, without taking into account the secondary reactions, would produce yields of $\approx 23 \%$ char, $\approx 13 \%$ gas and $\approx 64 \%$ tar, for complete ( $100 \%$ ) biomass degradation at $773 \mathrm{~K}$. Therefore, the yields produced in the simulation are pretty similar with those produced by the single particle models in the literature, since complete degradation of the particle would result to almost identical percentages. The shrinkage of the particles can also be seen on the product distribution illustrated in Figs. 9 and 10.

\section{Conclusions}

The effect of biomass shrinkage inside a bubbling fluidised was modelled and significant conclusions could be made.

Shrinkage does not have a significant effect on the momentum transport from the bubbling bed to the discrete biomass particles for small sizes in the order of $500 \mu \mathrm{m}$. The effect of shrinkage on momentum transport can be neglected when fluidised beds operate with such small particle sizes. However, the same cannot be stated for shrinkage parameters that shrink the particles close to their total dissintegration. The model excluded this extreme condition and studied particles that shrink until half of their initial volume.

For fast pyrolysis applications in lab-scale fluidised beds, small particle sizes are necessary (350-500 $\mu \mathrm{m})$ due to feeding problems. The effect of shrinkage on the pyrolysis of thermally thin particles does not have a significant impact neither on the product yields nor the pyrolysis time. Due to small Biot number, the progress of the reaction is only dependent on the heat transfer inside the particle and the effect of the chemical reaction rate is not significant. The results highly agree with already developed single particle models in the literature $[28,30]$.

Computational fluid dynamics models can give important information regarding the overall process of fast pyrolysis. They can efficiently used to derive important conclusions in the industrial sector, regarding the design and optimisation of bubbling fluidised bed reactors by deeply understanding the factors that highly influence the process.

\section{Appendix A. Mathematical model}

\section{A.1. Multiphase flow governing equations}

The simulations of the bubbling behaviour of the fluidised bed were performed by solving the equations of motion of a multifluid system. An Eulerian model for the mass and momentum for the gas (nitrogen) and fluid phases, was applied, while the kinetic theory of granular flow, was applied for the conservation of the solid's fluctuation energy. The governing equations are expressed in the following form.

\section{A.1.1. Mass conservation}

Eulerian-Eulerian continuum modelling is the most commonly used approach for fluidized bed simulations. The accumulation of mass in each phase is balanced by the convective mass fluxes. The phases are able to interpenetrate and the sum of all volume fractions in each computational cell is unity.

gas phase:

$\frac{\partial\left(\varepsilon_{g} \rho_{g}\right)}{\partial t}+\nabla \cdot\left(\varepsilon_{g} \rho_{g} v_{g}\right)=0$

solid phase:

$\frac{\partial\left(\varepsilon_{s} \rho_{s}\right)}{\partial t}+\nabla \cdot\left(\varepsilon_{s} \rho_{s} v_{s}\right)=0$

\section{A.1.2. Momentum conservation}

Newton's second law of motion states that the change in momentum equals the sum of forces on the domain. In gas-solid fluidised beds the sum of forces consists of the viscous force $\nabla \cdot \overline{\bar{\tau}}_{s}$, the solids pressure force $\nabla p_{s}$, the body force $\varepsilon_{s} \rho_{s} g$, the static pressure force $\varepsilon_{s} \cdot \nabla p$ and the interphase force $K_{g s}\left(u_{g}-u_{s}\right)$ for the coupling of gas and solid momentum equations by drag forces. gas phase:

$$
\begin{aligned}
\frac{\partial\left(\varepsilon_{g} \rho_{g} v_{g}\right)}{\partial t}+\nabla \cdot\left(\varepsilon_{g} \rho_{g} v_{g} \otimes v_{g}\right)= & -\varepsilon_{g} \cdot \nabla p+\nabla \cdot \overline{\bar{\tau}}_{g} \\
& +\varepsilon_{g} \rho_{g} g+K_{g s}\left(u_{g}-u_{s}\right)
\end{aligned}
$$


solid phase:

$$
\begin{aligned}
\frac{\partial\left(\varepsilon_{s} \rho_{s} v_{s}\right)}{\partial t} & +\nabla \cdot\left(\varepsilon_{s} \rho_{s} v_{s} \otimes v_{s}\right)=-\varepsilon_{s} \cdot \nabla p-\nabla p_{s}+\nabla \cdot \overline{\bar{\tau}}_{s} \\
& +\varepsilon_{s} \rho_{s} g+K_{g s}\left(u_{g}-u_{s}\right),
\end{aligned}
$$

where the solid-phase stress tensor is given by

$\overline{\bar{\tau}}_{s}=\varepsilon_{s} \mu_{s}\left(\nabla u_{s}+\nabla u_{s}^{T}\right)+\varepsilon_{s}\left(\lambda_{s}-\frac{2}{3} \mu_{s}\right) \nabla \cdot u_{s} \overline{\bar{I}}_{s}$,

and the Gidaspow interphase exchange coefficient

$K_{g s}=\frac{3}{4} C_{d} \frac{\varepsilon_{s} \varepsilon_{g} \rho_{g}\left|u_{s}-u_{g}\right|}{d_{s}} \varepsilon_{g}^{-2.65}$ for $\varepsilon_{g}>0.8$,

$K_{g s}=150 \frac{\varepsilon_{s}^{2} \mu_{g}}{\varepsilon_{g} d_{s}^{2}}+1.75 \frac{\varepsilon_{s} \rho_{g}\left|u_{s}-u_{g}\right|}{d_{s}}$ for $\varepsilon_{g} \leq 0.8$,

where the drag coefficient is given by

$C_{d}=\frac{24}{\varepsilon_{g} \operatorname{Re}_{S}}\left[1+0.15\left(\varepsilon_{g} \operatorname{Re}_{s}\right)^{0.687}\right]$,

and

$R e_{s}=\frac{d_{s} \rho_{g}\left|u_{s}-u_{g}\right|}{\mu_{g}}$.

The bulk viscosity $\lambda_{s}$ is a measure of the resistance of a fluid to compression which is described with the help of the kinetic theory of granular flows

$\lambda_{s}=\frac{4}{3} \varepsilon_{s} \rho_{s} d_{s} g_{0, s s}\left(1+e_{s s}\right) \sqrt{\frac{\Theta_{s}}{\pi}}$.

The tangential forces due to particle interactions are summarised in the term called solids shear viscosity, and it is defined as

$\mu_{s}=\mu_{s, c o l}+\mu_{s, k i n}+\mu_{s, f r}$,

where the collision viscosity of the solids $\mu_{s, \text { col }}$ is

$\mu_{s, \mathrm{col}}=\frac{4}{5} \varepsilon_{s} \rho_{s} d_{s} g_{0, s s}\left(1+e_{s s}\right) \sqrt{\frac{\Theta_{s}}{\pi}}$,

the frictional viscosity

$\mu_{s, \mathrm{fr}}=\frac{p_{s} \sin \left(\phi_{g s}\right)}{2 \sqrt{I_{2 D}}}$

and the Gidaspow [38] kinetic viscosity

$\mu_{s, k i n}=\frac{10 \rho_{s} d_{s} \sqrt{\Theta_{s} \pi}}{96 \varepsilon_{s} g_{0, s s}\left(1+e_{s s}\right)} \times\left[1+\frac{4}{5} \varepsilon_{s} g_{0, s s}\left(1+e_{s s}\right)\right]^{2}$.

The solids pressure $p_{s}$, which represents the normal force due to particle interactions, and the transfer of kinetic energy $\phi_{g s}$ are given by

$p_{s}=\varepsilon_{s} \rho_{s} \Theta_{s}+2 \rho_{s}\left(1+e_{s s}\right) \varepsilon_{s}^{2} g_{0, s s} \Theta_{s}$

and

$\phi_{g s}=-3 K_{g s} \Theta_{s}$.

\section{A.1.3. Fluctuation energy conservation of solid particles}

The solid phase models discussed above are based on two crucial properties, namely the radial distribution function $g_{0, s s}$ and granular temperature $\Theta_{s}$. The radial distribution function is a measure for the probability of interparticle contact. The granular temperature represents the energy associated with the fluctuating velocity of particles.

$$
\begin{aligned}
& \frac{3}{2}\left[\frac{\partial}{\partial t}\left(\varepsilon_{s} \rho_{s} \Theta_{s}\right)+\nabla \cdot\left(\varepsilon_{s} \rho_{s} u_{s} \Theta_{s}\right)\right] \\
& =\left(-p_{s} \overline{\bar{I}}_{s}+\overline{\bar{\tau}}_{s}\right): \nabla \cdot u_{s}+\nabla \cdot\left(k_{\Theta s} \cdot \nabla \cdot \Theta_{s}\right)-\gamma_{\Theta s} .
\end{aligned}
$$

where $\overline{\bar{\tau}}_{s}$ is defined in Eq. (8). The diffusion coefficient of granular temperature $k_{\Theta s}$ according to [38] is given by

$$
\begin{aligned}
k_{\Theta s}= & \frac{150 \rho_{s} d_{s} \sqrt{\Theta_{s} \pi}}{384\left(1+e_{s s}\right) g_{0, s s}}\left[1+\frac{6}{5} \varepsilon_{s} g_{0, s s}\left(1+e_{s s}\right)\right]^{2} \\
& +2 \rho_{s} d_{s} \varepsilon_{s}^{2} g_{0, s s}\left(1+e_{s s}\right) \sqrt{\frac{\Theta_{s}}{\pi}} .
\end{aligned}
$$

The radial distribution function $g_{0, s s}$ is defined as

$g_{0, s s}=\left[1-\left(\frac{\varepsilon_{s}}{\varepsilon_{s, \max }}\right)^{1 / 3}\right]^{-1}$

and the collision dissipation energy as

$\gamma_{\Theta s}=\frac{12\left(1-e_{s s}^{2}\right) g_{0, s s}}{d_{s} \sqrt{\pi}} \rho_{s} \varepsilon_{s}^{2} \Theta_{s}^{3 / 2}$.

An analytical discussion of the solid-phase properties can be found on Boemer et al. [39].

\section{A.2. Forces on discrete particles}

Assuming a spherical droplet with material density of $\rho_{d}$ inside a fluid, the rate of change of its velocity can be expressed as [40]

$\frac{\mathrm{d} u_{d}}{\mathrm{~d} t}=\frac{f}{\tau_{u}}\left(u_{\mathrm{con}}-u_{d}\right)+g\left(1-\frac{\rho_{\mathrm{con}}}{\rho_{d}}\right)+F_{v m}$,

where $f$ is the drag factor and $\tau_{u}$ the velocity response time

$\tau_{u}=\frac{\rho_{d} D^{2}}{18 \mu_{\mathrm{con}}}$

There are several correlations for the drag factor $f$ in the literature [41-43]. The one used in this study is the correlation of Putnam [43]

$f=1+\frac{\operatorname{Re}_{r}{ }^{(2 / 3)}}{6}$ for $R e_{r}<1000$

$f=0.0183 \operatorname{Re}_{r}$ for $1000 \leq \operatorname{Re}_{r}<3 \times 10^{5}$.

The second term on the right-hand side of the equation represents the gravity and boyancy force, while the third term represents the unsteady force of virtual mass force which is expressed as

$F_{v m}=\frac{\rho_{\text {con }} V_{d}}{2}\left(\frac{\mathrm{d} u_{\text {con }}}{\mathrm{d} t}-\frac{\mathrm{d} u_{d}}{\mathrm{~d} t}\right)$

According to Kolev [13], if bubble three-phase flow (i.e. solid particles in bubbly flow) is defined, two sub-cases are distinguished. If the volume fraction of the space among the solid particles, if they were closely packed is smaller than the liquid fraction (in this case the Eulerian sand)

$\varepsilon_{S}^{*}<\varepsilon_{S}$,

where

$\varepsilon_{s}^{*}=\frac{1-\varepsilon_{d m}}{\varepsilon_{d m}} \varepsilon_{d}$

then the theoritical possibility exists that the particles are carried only by the liquid. The hypothesis is supported if we consider the ratio of the free setting velocity in gas and liquid

$\frac{w_{d g}}{w_{d s}}=\sqrt{\frac{\rho_{d}-\rho_{g}}{\rho_{d}-\rho_{s}} \frac{\rho_{s}}{\rho_{g}}} \gg 1$.

Due to great differences between gas and liquid densities, the particles sink much faster in gas than in a liquid. Therefore, the drag force between gas and solid particle is zero and the drag force 

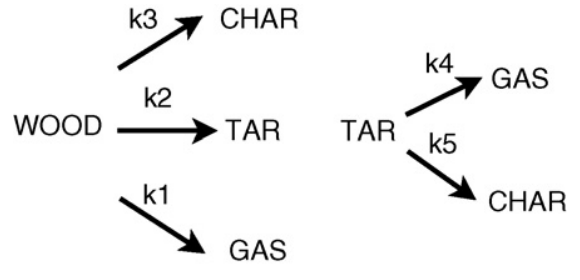

Fig. 11. Two-stage, semi-global model.

between solid and liquid is computed for a modified particle volume fraction $\varepsilon_{p}$

$\varepsilon_{p}=\frac{\varepsilon_{d}}{\varepsilon_{s}+\varepsilon_{d}}$

and an effective continuum viscosity $\mu_{\text {eff,con }}$

$\mu_{\text {eff,con }}=\left(1-\frac{\varepsilon_{p}}{\varepsilon_{d m}}\right)^{-1.55}$.

If the volume fraction of the space among the solid particles, if they were closely packed is larger than the liquid fraction

$\varepsilon_{S}^{*}>\varepsilon_{S}$,

then only

$\varepsilon_{d g}=\varepsilon_{d}\left(1-\frac{\varepsilon_{s}}{\varepsilon_{s}^{*}}\right)$

are surrounded by gas and the drag force can be calculated between one single solid particle and gas as for a mixture

$\varepsilon_{p}=\frac{\varepsilon_{d g}}{\varepsilon_{g}+\varepsilon_{d g}}$.

\section{A.3. Reaction kinetics}

The reaction kinetics of biomass pyrolysis is modelled using a two-stage, semi-global model. The mechanism is illustrated in Fig. 11.

The mechanism utilizes the Arrhenius equation which is defined as

$K_{i}=A_{i} \exp \left(\frac{-E_{i}}{R T}\right)$

The values of the kinetic parameters were obtained by Chan et al. [3] for the primary pyrolysis products, while the fourth and fifth reaction from Liden et al. [4] and Di Blasi [5], respectively. The model associates the reaction kinetics mechanism with the discrete biomass particle injected in the fluidised bed. The particle's properties change according to the reaction mechanism due to the phase transition phenomena. Momentum and heat transfer on the particle are calculated according to the its new condition in the UDF, and the variables associated with it updated in each time-step. Intraparticle secondary reactions due to the catalytic effect of char are taken into account, resulting on secondary vapour cracking.

\section{A.4. Heat transfer}

The heat conduction along the radius of the particle is calculated by solving the heat diffusion equation for an isotropic particle

$\frac{\partial}{\partial t}\left(\rho C_{p_{\text {eff }}} T\right)=\frac{1}{r^{2}} \frac{\partial}{\partial r}\left(k_{\text {eff }} r^{2} \frac{\partial T}{\partial r}\right)+(-\Delta H)\left(-\frac{\partial \rho}{\partial t}\right)$,

The boundary condition at the surface of the particle is given by

$h\left(T_{\infty}-T_{S}\right)=-\left.k_{e f f} \frac{\partial T}{\partial r}\right|_{r=R}$
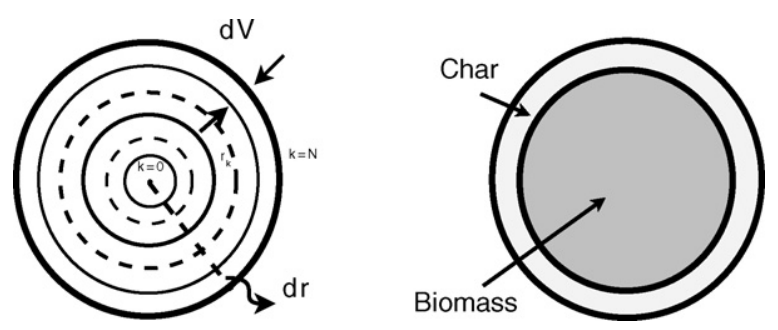

Fig. 12. (Right) Particle discretisation and discrete volume generation and (left) char formation during pyrolysis.

and at the centre of the particle

$\left.\frac{\partial T}{\partial r}\right|_{r=0}=0$.

The effective thermal conductivity $k_{\text {eff }}$ and effective specific heat capacity $C_{p_{e f f}}$ are given by

$k_{e f f}=k_{c}+\left|k_{w}-k_{c}\right| \psi_{w}$

$C_{p_{e f f}}=C_{p_{c}}+\left|C_{p_{w}}-C_{p_{c}}\right| \psi_{w}$.

The heat transfer coefficient is evaluated from the well-known Ranz-Marshall [34] correlation, when the particle is carried only by the fluidising gas

$N u=\frac{h d_{p}}{k}=2.0+0.6 \operatorname{Re}_{d}^{1 / 2} \operatorname{Pr}^{1 / 3}$.

However, assuming that conductive heat transfer is dominant in the near-particle-region, when the particle is inside the bed, the penetration theory can be applied with the following mixture properties [24]

$h_{\text {pen }}=\sqrt{\frac{k_{m}\left(\rho C_{p}\right)_{m}}{\pi \cdot t}}$

with

$k_{m}=\varepsilon_{g} k_{g}+\left(1-\varepsilon_{g}\right) k_{s}$

and

$\left(\rho C_{p}\right)_{m}=\varepsilon_{g} \rho_{g} C_{p, g}+\left(1-\varepsilon_{g}\right) \rho_{s} C_{p, s}$

The density of the particle is calculated as the sum of all the discrete densities that have been produced from the discretisation of the particle as it is illustrated in Fig. 12. The radius of the particle is discretised to $N$ number of grid points numbered from $k=0$ to $k=N$, where 0 is the centre of the particle, generating $N$ discrete volumes. The density distribution along the radius of the particle is calculated according to the discrete masses of the solid phases (wood and char) that correspond to the specific discrete volume. The discrete masses of the solid phases are calculated using a linear approximation between two neighbouring points that form a discrete volume, according to the mass fraction in time of the spesific phase.

The discrete volumes are given by

$d V_{k}=\frac{4}{3} \pi\left(r_{k}^{3}-r_{k-1}^{3}\right)$ for $k=1, \ldots, N$

where

$r_{k-1}=r_{k}-d r$.

The discrete mass $d m_{k}$ is calculated by

$d m_{k}=\frac{\left(\psi_{k w}+\psi_{k-1 w}\right)+\left(\psi_{k c}+\psi_{k-1 c}\right)}{2} \frac{m_{p}}{N}$ for $k=1, \ldots, N$ 
Therefore, the discrete particle densities $d \rho_{p_{k}}$ along its radius are given by

$d \rho_{p_{k}}=\frac{d m_{k}}{d V_{k}}$

and the total average particle density is

$\rho_{p_{a v}}=\frac{1}{N} \sum_{k=1}^{N} d \rho_{p_{k}}$.

\section{References}

[1] K. Papadikis, A.V. Bridgwater, S. Gu, CFD modelling of the fast pyrolysis of biomass in fluidised bed reactors. Part A: Eulerian computation of momentum transport in bubbling fluidised beds, Chemical Engineering Science 63 (2008) 4218-4227.

[2] K. Papadikis, S. Gu, A.V. Bridgwater, CFD modelling of the fast pyrolysis of biomass in fluidised bed reactors. Part B: heat, momentum and mass transport in bubbling fluidised beds, Chemical Engineering Science 64 (2009) 1036-1045.

[3] W.R. Chan, M. Kelbon, B.B. Krieger, Modelling and experimental verification of physical and chemical processes during pyrolysis of large biomass particle, Fuel 64 (1985) 1505-1513.

[4] A.G. Liden, F. Berruti, D.S. Scott, A kinetic model for the production of liquids from the flash pyrolysis of biomass, Chemical Engineering Communications 65 (1988) 207-221.

[5] C. Di Blasi, Analysis of convection and secondary reaction effect effects within porous solid fuels undergoing pyrolysis, Combustion Science Technology 90 (1993) 315-339.

[6] C.C. Pain, S. Mansoorzadeh, J.L.M. Gomes, C.R.E. de Oliveira, A numerical investigation of bubbling gas-solid fluidized bed dynamics in 2-D geometries, Powder Technology 128 (1) (2002) 56-77.

[7] S.V. Apte, K. Mahesh, T. Lundgren, A Eulerian-Lagrangian model to simulate two-phase/particulate flows, Centre for Turbulence Research, Annual Research Briefs, 2003.

[8] K.D. Kafui, C. Thornton, M.J. Adams, Discrete particle-continuum fluid modelling of gas-solid fluidised beds, Chemical Engineering Science 57 (2002) 2395-2410.

[9] G.A. Bokkers, J.A. Laverman, M. Van Sint Annaland, J.A.M. Kuipers, Modelling of large-scale dense gas-solid bubbling fluidised beds using a novel discrete bubble model, Chemical Engineering Science 61 (2006) 5590-5602.

[10] M. Ishii, N. Zuber, Relative motion and interfacial drag coefficient in dispersed two-phase flows of bubbles, drops and particles, Paper 56 a, in: AIChE 71st Ann. Meet., Miami, 1978.

[11] M. Ishii, T.C. Chawla, Local drag laws in dispersed two-phase flow, NUREG/CR1230, ANL-79-105, 1979.

[12] A. Tomiyama, Struggle with computational bubble dynamics, in: Third International Conference on Multiphase Flow, ICMF 98, Lyon, France, 1998.

[13] N.I. Kolev, Multiphase Flow Dynamics 2, Thermal and Mechanical Interactions, 2nd ed., Springer, 2005.

[14] M. Sommerfeld, Bubbly Flows: Analysis, Modelling and Calculation, Springer, 2004.

[15] D. Kunii, O. Levenspiel, Fluidization Engineering, 2nd ed., ButterworthHeinemann, 1991.

[16] B.R. Andeen, L.R. Glicksman, Heat Transfer to Horizontal Tubes in Shallow Fluidized Beds. ASMEpaper 76-HT-67, 1976.

[17] J.S.M. Boterill, Fluid-bed Heat Transfer, Academic Press, New York, 1975

[18] J.G. Yates, Fundamentals of Fluidised-bed Chemical Processes, Butterworths, London, 1983.
[19] P.K. Agarwal, Transport phenomena in multi-particle systems-IV. Heat transfer to a large freely moving particle in gas fluidized bed of smaller particles, Chemical Engineering Science 46 (1991) 1115-1127.

[20] M.S. Parmar, A.N. Hayhurst, The heat transfer coefficient for a freely moving sphere in a bubbling fluidised bed, Chemical Engineering Science 57 (2002) 3485-3494.

[21] A.P. Collier, A.N. Hayhurst, J.L. Richardson, S.A. Scott, The heat transfer coefficient between a particle and a bed (packed or fluidised) of much larger particles, Chemical Engineering Science 59 (2004) 4613-4620.

[22] A. Schmidt, U. Renz, Eulerian computation of heat transfer in fluidized beds, Chemical Engineering Science 54 (1999) 5515-5522.

[23] A. Schmidt, U. Renz, Numerical prediction of heat transfer in fluidized beds by a kinetic theory of granular flows, International Journal of Thermal Science 39 (2000) 871-885.

[24] J.A.M. Kuipers, W. Prins, W.P.M. Van Swaaij, Numerical calculation of wallto-bed heat-transfer coefficients in gas-fluidized beds, American Institute of Chemical Engineers Journal 38 (1992) 1079-1091.

[25] C.K. Lee, R.F. Chaiken, J.M. Singer, Charring pyrolysis of wood in fires by laser simulation, in: Proceedings of the 16th Symposium (International) on Combustion The Combustion Institute, Pittsburgh, 1976, pp. 1459-1470.

[26] W.R. Chan, M. Kelbon, B. Krieger-Brockett, Single-particle pyrolysis: correlations of reaction products with process conditions, Industrial and Engineering Chemistry Research 27 (1988) 2261-2275.

[27] J. Villermaux, B. Antoine, J. Lede, F. Soulignac, A new model for therma volatilization of solid particles undergoing fast pyrolysis, Chemical Engineering Science 41 (1986) 151-157.

[28] B.V. Babu, A.S. Chaurasia, Heat transfer and kinetics in the pyrolysis of shrinking biomass particle, Chemical Engineering Science 59(10)(May 2004) 1999-2012.

[29] A.S. Chaurasia, B.D. Kulkarni, Most sensitive parameters in pyrolysis of shrinking biomass particle, Energy Conversion and Management 48 (3) (March 2007) 836-849.

[30] C. Di Blasi, Heat, momentum and mass transport through a shrinking biomass particle exposed to thermal radiation, Chemical Engineering Science 51 (1996) $1121-1132$

[31] K. Papadikis, H. Gerhauser, A.V. Bridgwater, S. Gu, CFD modelling of the fast pyrolysis of an in-flight cellulosic particle subjected to convective heat transfer Biomass and Bioenergy 33 (January (1)) (2009) 97-107.

[32] D. Geldart, Types of Gas Fluidization, Powder Technology 7 (1973) 285

[33] A.V. Bridgwater, Principles and practice of biomass fast pyrolysis processes for liquids, Journal of Analytical and Applied Pyrolysis 51 (1999) 3-22.

[34] W.E. Ranz, W.R. Marshall, Evaporation from drops. Part I, Chemical Engineering Progress 48 (1952) 141-146.

[35] W.E. Ranz, W.R. Marshall, Evaporation from drops. Part II, Chemical Engineering Progress 48 (1952) 173-180.

[36] C. Di Blasi, Comparison of semi-global mechanisms for primary pyrolysis of lignocellulosic fuels, Journal of Analytical and Applied Pyrolysis 47 (1998) 43-64

[37] C.A. Koufopanos, N. Papayannakos, G. Maschio, A. Lucchesi, Modelling of the pyrolysis of biomass particles. Studies on kinetics, thermal and heat transfer effects, The Canadian Journal of Chemical Engineering 69 (1991) 907-915.

[38] D. Gidaspow, Multiphase Flow and Fluidization: Continuum and Kinetic Theory Descriptions, Academic Press, New York, 1994.

[39] A. Boemer, H. Qi, U. Renz, Eulerian simulation of bubble formation at a jet in a two-dimensional fluidized beds, International Journal of Multiphase Flow 23 (5) (1997) 927-944.

[40] C.T. Crowe, M. Sommerfield, Y. Tsuji, Multiphase Flows with Droplets and Particles, CRC Press LLC, 1998.

[41] L. Schiller, A. Naumann, Uber die grundlegenden Berechungen bei der Schwerkraftaufbereitung, Vereines Deutscher Ingenieure 77 (1933) 318

[42] R. Clift, W.H. Gauvin, The motion of particles in turbulent gas streams, in: Proc Chemeca '70, 1, 14., 1970

[43] A. Putnam, Integrable form of droplet drag coefficient, ARS JNl. 31 (1961) 1467. 